\title{
Desarraigo y cuestión multicultural en los flujos migratorios poscoloniales ${ }^{1}$
}

WoOLdy Edson Louidor

Pontificia Universidad Javeriana (Colombia)

\section{La cuestión multicultural en la era de la globalización y la poscolonialidad}

Hablar de multiculturalismo(s) en un contexto de globalización suena menos extraño hoy que hace más de 40 años, aunque la convivencia entre diferentes formas de vida y el respeto por la diversidad son prácticas tan viejas como la misma humanidad (Kymlicka, 2012, p. 5).

1 Este artículo es resultado del proyecto de investigación La heterogeneidad del sujeto migrante haitiano, financiado por el Instituto de Estudios Sociales y Culturales Pensar de la Pontificia Universidad Javeriana. Este proyecto es parte de la investigación esencialmente teórica que, desde la línea de investigación en Estudios Migratorios del Instituto, su autor viene desarrollando a partir de agosto de 2015, en el marco de construcción de "la epistemología de los estudios migratorios”. Dicha construcción tiene como objetivo articular una reflexión crítica y creativa sobre las condiciones de posibilidad, los límites y la producción del conocimiento en general (a través de categorías, paradigmas, enfoques teóricos y metodológicos) en torno a la migración como problema de conocimiento, como objeto de políticas públicas y leyes y como realidad vivida. 
La "cuestión multicultural" 2 ocupa hoy un importante lugar tanto en los debates filosóficos sobre la "comprensión misma de la democracia”, la ciudadanía, el derecho (por ejemplo, la relación entre el "derecho racional-universal" de los Estados democráticos y las diferencias particulares de raza, sexo o pertenencia étnica) como en los debates políticos y jurídicos sobre cómo acomodar las diferencias étnicas y nacionales "sin comprometer los principios políticos liberales fundamentales” (Forero Reyes, 2008, p. 254).

Entre las variadas condiciones de la emergencia, de manera intensificada, de la cuestión multicultural en la posguerra, Stuart Hall (2000) subraya de manera particular el "fenómeno de lo poscolonial”, tras la irrupción -principalmente de 1947 a 1965- de varias luchas contra la colonización, la segregación racial y a favor de los derechos de las minorías étnicas. Además, coincide con ambos fenómenos -lo multicultural y lo poscolonial- la promoción de los ideales de los derechos humanos, que arrancó con la Declaración Universal de los Derechos Humanos promulgada por la Organización de las Naciones Unidas (ONU) en 1948 y culminó con la publicación de un gran plexo de instrumentos de derechos humanos en las décadas posteriores.

Paradójicamente, a pesar de que hoy en día la humanidad haya logrado una de sus mayores conquistas con una conciencia muy nítida de la importancia sagrada de los derechos humanos y la dignidad humana (Bobbio, 1991), con una enorme facilidad para superar las distancias en el tiempo y el espacio (la llamada "compresión espacio-temporal”) debido a los impresionantes "progresos" tecnológicos y con un tejido cada vez más entrelazado de interdependencia de seres humanos, culturas y países; sin embargo, los migrantes, en particular quienes están obligados a emigrar (refugiados, solicitantes de asilo, migrantes forzados en general y con necesidad de protección internacional), enfrentan una creciente vulnerabilidad y se ven cada vez más expuestos a violaciones de sus derechos e incluso a la muerte

2 Debemos esta expresión a Stuart Hall en el capítulo titulado Conclusion: the multi-cultural Question que escribió en el libro Un/settled Multiculturalisms: Diasporas, Entanglements, 'Transruptions' (New York, 2000). 
en sus trayectorias hacia otros países y en sus esfuerzos por integrarse en las sociedades de llegada. Los naufragios en el Mediterráneo, en los que miles de refugiados y migrantes sirios y africanos perdieron la vida recientemente en busca de protección internacional y acogida en la Unión Europea, son un testimonio elocuente de los dramas de esta población vulnerable.

Como lo afirmó Amnistía Internacional (2013), el mundo es un lugar peligroso para los migrantes, incluyendo la mayoría de los 244 millones de migrantes internacionales ${ }^{3}$ que existen actualmente en el mundo, según la Organización de las Naciones Unidas (2016), así como los 59.5 millones de personas desplazadas forzadamente (de las cuales 19.5 millones de refugiados, 38.2 millones de desplazados forzados internos y 1.8 millones de solicitantes de asilo). Los Estados, principalmente los del primer mundo (la Unión Europea, los Estados Unidos de América, Japón, Australia, etc.), adoptan políticas restrictivas orientadas a obstaculizar e impedir la llegada y acogida de refugiados, migrantes con necesidad de protección internacional y principalmente aquellas personas, familias y comunidades originarias de países pobres o consideradas "peligrosas" (en particular por el llamado "terrorismo").

Por ejemplo, es inconcebible que, en pleno siglo XXI, un candidato presidencial estadounidense que desarrolló a lo largo de su campaña un discurso antiinmigrante y abiertamente xenófobo haya ganado la presidencia de este país, con un gran apoyo entre los electores estadounidenses y a pesar de las acérrimas críticas de parte de dicha sociedad y del mundo en general.

Como consecuencia de ello, los refugiados y migrantes se vuelven desarraigados por haber sido obligados, la mayoría de ellos, a huir de sus territorios de origen por un plexo de factores de expulsión y a no obtener un lugar de acogida en los países de llegada o en las puertas de entrada a dichos países (en particular, en las fronteras por tierra y mar). Cada vez más se cierran las fronteras, se endurecen las políticas migratorias y de asilo, y, como lo afirmó el papa Francisco, "se

3 Migrante internacional es toda persona que no vive en su país de origen. Las Naciones Unidas no incluyen en esta categoría a los refugiados y los solicitantes de asilo. 
globaliza la indiferencia" frente al desarraigo de dichos migrantes y refugiados, a la crisis humanitaria y los vacíos de protección internacional que afrontan desesperadamente.

En este capítulo, esencialmente teoríco, vamos a escrutar las tres categorías del "desarraigo", lo "poscolonial” y lo "multicultural”, desde las siguientes preguntas: ¿Qué es el desarraigo en este nuevo sistema global poscolonial? ¿Cuáles son sus diferentes rostros y factores de producción? (Parte 1) ¿Cómo comprender la dimensión poscolonial de los actuales flujos migratorios, en un mundo "ambivalente" en el que, por un lado, aumenta de manera exponencial el número de migrantes internacionales, refugiados y solicitantes de asilo; y, por el otro lado, cada vez más los Estados -principalmente los del primer mundo- endurecen sus políticas migratorias y de refugio para negar a dichos migrantes la acogida, la protección internacional y la integración? (Parte 2) ¿Qué papel juega el mito de la nación y sus fetichismos (ciudadanía, identidad, soberanía) en la dificultad de acoger al otro diferente y extranjero, y de construir sociedades multiculturales? (Parte 3) ¿Cómo superar, con base en un nuevo multiculturalismo, este mito en un mundo líquido y el "nuevo internacionalismo" protagonizado por migrantes, exiliados, refugiados, diásporas y otras subjetividades desterritorializadas? (Parte 4).

\section{Desarraigo: sus diferentes rostros y factores en el actual contexto poscolonial}

El desarraigo es planteado por Saskia Sassen como uno de los principales problemas de las migraciones contemporáneas. La socióloga la define como la destrucción o pérdida de sus hogares, por parte de un gran plexo de personas y comunidades que se ven de un día a otro obligadas a buscar otro hogar. Ella señala un "nuevo conjunto de migraciones”, cuyos “epicentros son el Mediterráneo, el Mar de Andamán y América Central" y cuyas causas: 
No son tanto la búsqueda de una vida mejor, sino conflictos asesinos, guerras, el acopio masivo de tierras para plantaciones, la destrucción de sus hábitats a través de la contaminación de la tierra y el agua, las sequías, la desertificación, el resurgimiento de la minería para obtener los metales que necesitamos para nuestra revolución electrónica. Familias y comunidades enteras están siendo expulsadas de su territorio de origen. Cada vez quedan menos 'hogares' a los que volver (Sassen, 2015).

"Estos flujos bien pueden ser los inicios de nuevas historias y geografías hechas por hombres, mujeres y niños en la huida desesperada de condiciones insostenibles" y para quienes "no hay hogar adonde volver, su hogar se ha convertido en una plantación, una zona de guerra, una ciudad privada, un desierto o una llanura inundada" (Sassen, 2015). Los desarraigados son seres humanos sin hogar, sin mundo y se encuentran en otros territorios o en "errancia" buscando un nuevo hogar. Son nuevos flujos constituidos principalmente por refugiados y otros migrantes forzados que fueron obligados a huir de sus territorios, por estar atrapados en medio de trincheras, en sus hábitats destruidos por bombas, desastres naturales, iniciativas de megaproyectos de minería y desarrollo. Son personas que perdieron totalmente o en gran parte sus hogares y territorios, y no tienen ninguna posibilidad (por lo menos, a corto plazo) de regresar a ellos.

El desarraigo no es un fenómeno totalmente nuevo en el mundo ya que existía por ejemplo en las Américas desde la llegada de los conquistadores españoles a este continente en 1492 y, de manera masiva, en el siglo XVI con la trata de las poblaciones africanas arrancadas de sus hogares en África en el marco del comercio transatlántico y trasplantadas por los colonizadores europeos al "continente exilio" para trabajar como esclavos en las plantaciones del "Nuevo Mundo". Los esclavizados africanos no tuvieron la posibilidad de volver a sus hogares: fueron arrancados de sus raíces y han tenido que re-crearse en el Nuevo Continente; así como tampoco los indios han vuelto a recuperar sus territorios, despojados por los conquistadores y colonizadores europeos y luego por los neo-colonizadores criollos tras las independencias latinoamericanas (Louidor, 2016). 
¿Cuál es pues lo novedoso del desarraigo en nuestro actual contexto? ¿En qué consiste el "nuevo desarraigo”, por así decirlo? ¿Cuáles son sus factores y sus rostros? Justamente una de las importantes novedades del desarraigo de hoy es el actual sistema global poscolonial. Los desarraigados de hoy no son esclavos de colonias ni provienen de sociedades colonizadas aún por sociedades colonialistas: ya no existen (casi) estos tipos de relaciones coloniales en las que las metrópolis administran las colonias. Los actuales desarraigados son más bien víctimas de "un sistema de poder globalizado asimétrico que es posnacional, transnacional y neocolonial”, nos dice Stuart Hall (2000, p. 212): un sistema caracterizado por "la desigualdad estructural dentro de un sistema de libre mercado desregulado y libre flujo de capital dominado por el primer mundo y programas de reajuste estructural en los que los intereses y modelos de gobernanza occidentales son supremos" (Hall, 2000, p. 213).

Este nuevo sistema de poder globalizado necesita para su funcionamiento la tierra para extraer los metales, el petróleo y otros recursos naturales valiosos con miras a alimentar y sostener la exigente revolución tecnológica; necesita depredar la biodiversidad mediante la explotación industrial y tecnológica para mantener el desarrollo y el alto nivel de vida en los países desarrollados (primer mundo). Si bien los países subdesarrollados (en África y en América Latina, por ejemplo) siguen siendo una reserva de materias primas y manos de obra baratas para este sistema; sin embargo, la justificación que se usa para explotar dichas materias y manos de obra es diferente hoy: para ello se invoca no la colonización, la esclavitud (o servidumbre) o el derecho de propiedad colonial, sino el desarrollo, el libre mercado, el progreso económico y la eficiencia, entre otros. Además, quienes explotan dichos recursos no son tanto los Estados o las naciones (como lo fue en los tiempos de la Colonia), sino empresas transnacionales al servicio del capitalismo global. Ya estamos en presencia de un nuevo sistema con nuevos actores, mecanismos, justificaciones y víctimas.

Sin embargo, los impactos que tiene este sistema global poscolonial siguen siendo los mismos que en los tiempos de la colonización: el despojo de comunidades originarias de su fuerza de trabajo y de sus territorios ancestrales, la esclavización de la mano de obra local, 
la precarización de los derechos de los trabajadores, las guerras asesinas por el control del territorio (apoyadas por las élites del poder estatal e incluso por políticas públicas), la contaminación de los hábitats (tierra, agua y aire), la violación del derecho a la ciudad y finalmente la destrucción de los hogares (en el campo y en la ciudad) de los más pobres entre los pobres.

En el caso concreto de América Latina, bajo el neoliberalismo este sistema global poscolonial ha sido implantado en nuestra región, primero en Chile en los años setenta y luego en México en 1982. "Las políticas neoliberales se convirtieron en la vía para extender los cambios económicos en América Latina" (Gogol, 2004, p. 152), mediante dos grandes procesos. Primero, la industrialización por sustitución de importaciones (patrocinada por los Estados y la Comisión Económica para América Latina y el Caribe-CEPAL-) que habría fomentado el desarrollo de las economías semi-dependientes y nacionalistas en la región. Segundo, la imposición de las políticas llamadas de ajuste estructural a través de rigurosas condiciones de reestructuración de la deuda, la privatización de las compañías en poder del Estado, el incremento de la inversión extranjera directa, la devaluación de la moneda, los drásticos cortes obligatorios en los gastos sociales (la llamada austeridad), entre otras.

Como consecuencia de ello, los voraces apetitos del neoliberalismo han engendrado hambre y exclusión a lo largo y ancho de nuestra región. "En América Latina, la pobreza, de hecho, la indigencia, ha devenido un modo de vida", afirmó Eugene Gogol (2004, p.152). En este sentido, Isabel Álvarez Echandi argumenta lo siguiente, relacionando estas consecuencias desastrosas del sistema global poscolonial hegemónico con las migraciones en América Latina:

En la actualidad el tema de las migraciones continúa siendo parte de la realidad política, social y económica de la región en el contexto de la globalización. En las democracias latinoamericanas parece existir un divorcio entre el Estado y los derechos sociales y económicos de amplios grupos de la sociedad. Los altos grados de pobreza, desigualdad y desempleo, han vuelto a América Latina una región expulsiva. Actualmente, $53 \%$ de los latinoamericanos estaría dispuesto a migrar 
si tuviera la posibilidad. Más de 20 millones de personas residen fuera de sus países de origen $(2012, \text { p. } 7)^{4}$.

Los factores de expulsión se agravan cada vez más en América Latina debido a la profundización de la pobreza, la desigualdad, el desempleo, la exclusión y los impactos perjudiciales de los modelos de desarrollo para las comunidades originarias (afroamericanas e indígenas), así como a consecuencia de la violencia (el conflicto armado en Colombia, el posconflicto -particularmente en Centroamérica-y la delincuencia organizada por culpa del narcotráfico y otras actividades criminales en México) y la violación sistemática de los derechos humanos (civiles, políticos, económicos, sociales y culturales) a lo largo y ancho de la región.

En resumen, la categoría de lo poscolonial indica que estamos en una transición: del fin del colonialismo entendido como "el aparato de dominio político y militar colonialista en aras de garantizar la explotación del trabajo y las riquezas de las colonias en beneficio del poder colonizador" (Castro-Gómez y Restrepo, 2008, p. 24), hacia una nueva configuración de poder en la que hay a la vez continuidades y cambios. Por ejemplo, continúan en las excolonias "los problemas de dependencia, subdesarrollo y marginalización”, pero están re-articulados bajo la forma de "luchas entre fuerzas sociales autóctonas" comprendidas como "contradicciones internas" y "fuentes de desestabilización dentro de la sociedad descolonizada o entre ella y el sistema global más grande" (Hall, 2000, p. 213). Esta nueva reconfiguración de poder cambia sustancialmente las relaciones entre las sociedades descolonizadas y las sociedades excolonialistas y, sobre todo, entre aquellas y el sistema global que reintroduce, según Santiago Castro-Gómez y Eduardo Restrepo (2008, p. 24), “nuevas formas de colonialidad [del ser, del poder y del saber] articuladas al capitalismo posfordista y, al mismo tiempo, nuevas formas (molares y moleculares) de resistencia ('decolonialidad')".

4 Hoy día existen 28.5 millones de latinoamericanos y caribeños que residen en países distintos al de su nacimiento. Véase CEPAL (2014). 
Los factores histórico-estructurales, tales como la permanencia e incluso agudización de los problemas económicos, sociales y políticos poscoloniales o derivados de la colonización y la penetración violenta del nuevo sistema global hegemónico de carácter capitalista-neoliberal, han contribuido a desarraigar a muchos ciudadanos de las sociedades descolonizadas a lo largo de las últimas décadas. Dichos ciudadanos se han dirigido en gran parte hacia los países ex colonialistas, convirtiéndose así en "migrantes poscoloniales". Por ejemplo, migrantes, refugiados y solicitantes de asilo provenientes de África, Asia, el Caribe y Latinoamérica se han dirigido a sus antiguas metrópolis, constituyéndose así en comunidades relativamente grandes en dichos territorios. Si bien estas subjetividades poscoloniales tienen la facilidad lingüística e histórico-cultural y otras facilidades para integrarse como minorías en las excolonias; sin embargo, sufren del racismo y otras formas latentes o manifiestas de discriminación en virtud justamente del peso racista-colonial aún vigente en las antiguas metrópolis. Son numerosos los casos de discriminación e incluso de xenofobia en contra de latinos en España; de puertorriqueños en los Estados Unidos de América; de caribeños franco-hablantes (martiniqueses, guadalupanos, guyaneses, haitianos, etc.) en Francia; de africanos y asiáticos en Francia y en Gran Bretaña, etc., por citar solo algunos ejemplos.

Edouard Glissant explica lo siguiente a modo de ilustración:

El emigrado antillano en Francia es ambiguo. Lleva una vida de emigrado, pero tiene el estatuto de ciudadano. Puede incluso ser funcionario: enfermera, empleado de oficinas postales, oficial aduanero en Orly o agente de policía. Se siente francés, pero sufre de las formas latentes o declaradas de racismo, del mismo modo que un Árabe o un Portugués (1997, p. 127).

Este caso ilustra la situación de los sujetos poscoloniales que si bien tienen automáticamente la nacionalidad de los países excolonialistas (los puertorriqueños en los Estados Unidos de América, por ejemplo), pero siguen siendo víctimas de racismo al igual que otros migrantes y extranjeros. De hecho, es más grave la situación de aquellos sujetos 
poscoloniales que ni siquiera cuentan con la nacionalidad de los países excolonialistas, porque se convierten en migrantes “indocumentados" y enfrentan una triple discriminación: por su origen nacional poscolonial, su condición de migrantes/extranjeros y su estatus migratorio indocumentado. Es sustancialmente el drama de los migrantes y refugiados africanos.

Por lo tanto, los rostros del desarraigo en el actual contexto poscolonial son muy heterogéneos entre sí, ya que los sujetos desarraigados son diversos unos de otros. Podemos intentar caracterizar dichos rostros en los tres siguientes grandes grupos:

a. Los que se quedan atrapados entre su lugar de origen y el lugar de llegada. Se trata de aquellos que fueron obligados a dejar sus territorios a consecuencia de un gran plexo de factores (desastres naturales, megaproyectos de desarrollo y minerías, guerra, etc.), pero no encuentran aún un lugar de acogida para "habitar", tampoco tienen un hogar adonde regresar. Son los desarraigados sin hogar que mencionó Saskia Sassen;

b. Los desarraigados que Judith Butler llama sin-estados porque los territorios en los que se encuentran son escenarios de guerras o simplemente no constituyen un lugar de derecho para ellos. En el mundo actual hay muchos casos de sin-estados tales como: los prisioneros de Guantánamo (acusados de terrorismo por los Estados Unidos de América) que fueron llevados a una prisión donde no hay un Estado en el sentido territorial, "aunque sean delegados del poder estatal los que controlan y siembran el terror entre los habitantes del territorio"; los palestinos de la Franja de Gaza, considerada como "una prisión al aire libre" en la que se encuentran prácticamente recluidos; los ciudadanos de Afganistán e Irak que son miembros de "poblaciones enteras [que] abandonan un estado de guerra, un estado diferente del estado concebido como el lugar de los derechos, deberes y protección jurídica" (Butler y Spivak 2009, p. 48);

c. Finalmente, los desarraigados que si bien son acogidos en algún lugar de llegada (algunos ni siquiera necesitan visas o residencia 
para instalarse en dicho lugar, como los martiniqueses, los guyaneses, los puertorriqueños, etc.), pero se ven obligados a abandonar sus culturas, esconder sus identidades “originales" en lugares públicos o darles menos importancia (utilizar estrategias de adaptación y asimilación) para poderse “integrar” en las sociedades de acogida. En este grupo podemos ubicar a los migrantes poscoloniales que enfrentan un tipo bien particular de desarraigo. Volvemos en la segunda parte sobre este grupo de desarraigados que nos interesa en este capítulo.

Esos tres grupos de desarraigados tienen en común la característica de ser heterogéneos; es decir, diferentes unos de otros y también diferentes de las sociedades adonde llegan. Su heterogeneidad plantea el reto de la multiculturalidad (cómo acomodar su diversidad en la cultura territorializada de la sociedad de llegada para construir una vida común, sin obligarles a renunciar a su "identidad") a las sociedades de llegada que, en muchos casos, se siguen aferrando al mito moderno excluyente-sólido-indolente de la nación y sus fetichismos ("Estado nacional", "cultura nacional", "valores nacionales").

\section{Las migraciones poscoloniales en un mundo ambivalente}

Las migraciones poscoloniales tienen la particularidad de hacer resurgir la "cuestión colonial" dentro de las sociedades excolonialistas (el regreso de lo "colonial" a la metrópoli que algunos califican de "revancha" histórica, "invasión pacífica”). Además, en muchos casos, las excolonias de las que provienen dichas migraciones se liberaron hace poco más de medio siglo de sus colonizadores. Tomemos algunos ejemplos.

Tras la Segunda Guerra Mundial, los dos continentes africano y asiático tuvieron una intensa lucha de descolonización entre 1947 y 1985 aproximadamente. Varios países se independizaron en este contexto, tales como: la India (1947), Pakistán (1947), Singapur (1963), 
Congo (1960), Libia (1951), Sudán (1956), Túnez (1956), Guinea (1958), etc. En el Caribe también se independizaron Jamaica (1962) y varias islas de las Antillas menores tales como Antigua y Barbuda (1981), Dominica (1978), etc.

Vale subrayar también las distintas luchas de las minorías étnicas en contra de la segregación racial. Es el caso del movimiento de los negros de Sudáfrica contra el apartheid y del movimiento norteamericano por los Derechos Civiles de los afroamericanos, entre 1955 y 1965; así como las diferentes luchas por el multiculturalismo y los derechos de las minorías (en especial, las poblaciones indígenas y grupos sub-nacionales) que emergieron a finales de los años sesenta. Si bien estas poblaciones segregadas y "minorías étnicas" no son migrantes poscoloniales propiamente dichos, su combate jugó un papel muy importante durante la posguerra (en particular en las décadas del sesenta y ochenta), en la reducción de la discriminación contra las minorías culturales, religiosas o raciales y en la emergencia de varias formas de multiculturalismo orientadas a intentar poner fin a las desigualdades económicas, la baja representación política, la estigmatización social y la invisibilidad cultural de algunas formas de vida (Kymlicka, 2012, p. 6). Tarea que sigue aún pendiente.

Las conquistas de los movimientos sociales han llevado a los organismos internacionales, tales como la Organización de las Naciones Unidas (ONU), en particular la Organización de las Naciones Unidas para la Educación, la Ciencia y la Cultura (Unesco), y la Organización Internacional del Trabajo (OIT) a desarrollar instrumentos de derecho internacional para promover y defender los derechos humanos de las poblaciones, grupos o minorías étnicos, raciales y nacionales. Vale subrayar la Declaración de los Derechos de las Personas Pertenecientes a Minorías Nacionales, Étnicas, Religiosas o Lingüísticas (ONU, 1992), la Declaración de los Pueblos Indígenas (ONU, 2007), la Declaración Universal sobre Diversidad Cultural (Unesco, 2001), el Convenio número 169 sobre Pueblos indígenas y Tribales (OIT, 1989), entre otros instrumentos ${ }^{5}$.

5 Véase Kymlicka, 2007. 
Una de las consecuencias de la multiplicación de dichos instrumentos de protección, apoyados en fuertes movimientos políticos y sociales protagonizados por estas mismas poblaciones, ha consistido en romper con el esquema "monocultural" con el que se han venido construyendo nuestros Estados-nación. Dicho esquema sigue siendo reivindicado por sectores étnicos o socio-políticos que se aferran a la supuesta necesidad de construir y defender la homogeneidad nacional (confundiendo la nación con su propia identidad) como única base cultural de la sociedad, con exclusión de los "otros" diferentes. De hecho, los Estados se han venido poco a poco abriendo a la posibilidad de incluir cierto nivel de multiculturalidad en sus legislaciones y políticas, renunciando en parte a sus tendencias "asimilacionistas" (posibilidad que ha conocido cierto estancamiento o retroceso). Las políticas multiculturales se refieren en general a la "acomodación política y legal de la diversidad étnica que emergió en el Occidente como el vehículo para reubicar las viejas formas de jerarquía étnica y racial dentro de nuevas relaciones de ciudadanía democrática" (Kymlicka, 2012, p.1).

Banting y Kymlicka identifican las ocho (8) políticas multiculturales, más aplicadas por los Estados en relación con las minorías en general:

a. Afirmación constitucional, legislativa o parlamentaria del multiculturalismo, a nivel central, regional o municipal;

b. Introducción del multiculturalismo en el currículo escolar;

c. Inclusión de la representación de lo étnico y sensibilidad hacia ello en el mandato de los medios de comunicación públicos;

d. Excepciones en materia de vestimenta, legislación relativa al descanso dominical, etc. (por estar consagradas en las leyes o en razón de sentencias judiciales);

e. Admisión de la doble nacionalidad;

f. Apoyo financiero a las actividades culturales desarrolladas por las organizaciones étnicas;

g. Financiación de la educación bilingüe o en la lengua nativa;

h. Discriminación positiva en favor de los grupos inmigrantes desfavorecidos (Kymlicka 2007, p. 87). 
Según Will Kymlicka, “cada una de esas políticas ha sido defendida como un medio para superar las herencias de las anteriores jerarquías y ayudar a crear sociedades democráticas más justas y más incluyentes" (2012, p. 8). Pero el autor canadiense identifica también ciertas condiciones (cuestionables algunas de ellas, como por ejemplo el control de las fronteras) que habrían podido facilitar un poco más el "éxito" de estas políticas, tales como:

- La desecuritización de las relaciones étnicas;

- El compromiso con los derechos humanos a través de las líneas étnicas y religiosas;

- El control de las fronteras, principalmente cuando la sociedad siente temor frente al ingreso de grandes olas de inmigrantes indocumentados y de solicitantes de asilo;

- La diversidad de los grupos inmigrantes que llegan a la sociedad de llegada;

- La valoración de la contribución económica de los inmigrantes (Kymlicka 2012, p. 2).

Paradójicamente, esta emergencia e implementación "mitigada" de las políticas multiculturales orientadas a "crear sociedades democráticas más justas y más incluyentes" se han venido enfrentando a la xenofobia, en particular contra los migrantes poscoloniales y los refugiados. En el caso concreto de las migraciones poscoloniales, ha sido muy difícil construir sociedades multiculturales; es decir, sociedades capaces de superar los problemas derivados de "las características sociales y los problemas de gobierno planteados por cualquier sociedad en la cual diferentes comunidades culturales conviven juntas y tratan de construir una vida común conservando algo de su identidad 'original'” (Hall, 2000, p. 210). Lo multicultural ha sido un reto muy difícil, principalmente para las sociedades excolonialistas en las que se considera inferior la identidad "original" de los ex colonizados: "latinos", “africanos”, “árabes”, “caribeños”, “negros”, “creoles”, “chicanos”, etc., no son calificativos totalmente positivos en estas sociedades excolonialistas, porque llevan tras ellos una pesada carga semántica e histórica negativa. 
Del mismo modo, todos los multiculturalismos, a saber, el conjunto de "estrategias y políticas adoptadas para gobernar y manejar los problemas de diversidad y multiplicidad que sociedades multiculturales generan" (Hall, 2000, pp. 210-211), no han tenido los resultados esperados. Así como han existido múltiples multiculturalidades, dependiendo cada una de la característica propia de la sociedad multicultural en cuestión (la multiculturalidad colombiana es diferente a la multiculturalidad chilena, peruana, norteamericana, etc.), ha habido múltiples multiculturalismos: desde el multiculturalismo conservador hasta el multiculturalismo plural, pasando por los multiculturalismos de tipo pluralista, corporativo, revolucionario, etc. (Hall, 2000, pp. 210-211).

Entonces, ¿cuáles han sido las políticas multiculturales específicas aplicadas a los inmigrantes para gobernar y manejar la diversidad propia de estos sujetos? ¿Por qué han fracasado? Will Kymlicka explica que primero se tiene que entender que existen varios tipos de grupos minoritarios que plantean retos diferenciales para la acomodación de su diversidad; por ejemplo, la diversidad cultural propia de los indígenas y las minorías nacionales (como los vascos y catalanes en España, los quebequeses en Canadá, los flamencos en Bélgica, por ejemplo) es muy diferente a la diversidad cultural de los inmigrantes, cuya "especificidad se manifiesta fundamentalmente en su vida familiar y en las asociaciones voluntarias, algo que no resulta contradictorio con su integración institucional” (Kymlicka, 1996, p. 31).

En el caso de los migrantes de hoy (incluyendo los migrantes poscoloniales) que llegan a un Estado, ellos no conforman (ni quieren hacerlo) una "nación”; es decir, "una comunidad histórica, más o menos completa institucionalmente, que ocupa un territorio o una tierra natal determinada y que comparte una lengua y una cultura diferenciadas" (Kymlicka 1996, p. 26); tampoco ocupan tierras ancestrales (por ejemplo, aunque los latinos pueden reconocer que sus ancestros lejanos fueron españoles, pero no hacen valer su "genealogía” para reclamar tierras y derechos en España). Aunque la mayoría de los inmigrantes rechazan la asimilación como única manera de ser integrados a la sociedad de llegada; sin embargo, no quieren construir una sociedad paralela (latina, africana, caribeña, etc.) dotada de autogobierno. A lo sumo, reclaman su "derecho a expresar su 
particularidad étnica”, pero "dentro de las instituciones públicas” del país de llegada. Los retos que las minorías migrantes plantean para su incorporación en la sociedad de llegada son muy diferentes a los retos que derivan de la integración de otras minorías, por ejemplo las poblaciones indígenas y las minorías sub-estatales quienes reclaman sus derechos al autogobierno, a la autonomía de sus territorios y a sus usos y costumbres.

Como resultado de la migración muchos países han terminado por volverse "poliétnicos", según Will Kymlicka, ya que sus respectivos Estados han fomentado (hoy en día, cada vez menos, como lo veremos) la no asimilación de los inmigrantes y la polietnicidad (reconociendo por ejemplo que sus habitantes provienen de naciones distintas y tienen derecho a expresarlo en el todo nacional), pero no tratan a los inmigrantes como si constituyeran una nación. Por lo tanto, Will Kymlicka propone utilizar la categoría de multiculturalismo en dos sentidos que deben ser claramente distinguidos, de acuerdo con la misma naturaleza de las dos formas de diversidad cultural correspondientes. Por un lado, existe una forma poliétnica de diversidad cultural, cuando la diversidad deriva de la inmigración individual y familiar procedente de diversas naciones y lleva a un Estado a adoptar políticas de apoyo a la polietnicidad (Kymlicka, 1996, p. 34). Mientras que la forma multinacional de diversidad cultural es el "resultado de la colonización, la conquista o la confederación de comunidades nacionales” (Kymlicka, 1996, pp. 34-35) y supone "un aspecto importante de la identidad personal y la vida política” (Kymlicka, 1996, p. 36).

Justamente hoy en día, la multiculturalidad plantea serios problemas para las sociedades excolonialistas, principalmente en Occidente, que rechazan tanto a los migrantes como a los excolonizados (vistos como potencial amenaza), debido al temor que les genera el llamado "terrorismo". Se cierra cada vez más la posibilidad de seguir construyendo (construcción que se implementó en Occidente, desde la década de los setenta hasta la mitad de los noventa) sociedades que acepten la diversidad cultural (poliétnica y multicultural) y la apoyen. Se observa un retroceso significativo en cuanto a la promoción y aplicación de políticas multiculturales en Occidente; por lo que incluso algunos líderes políticos han declarado el fracaso y 
la muerte del multiculturalismo (Kymlicka, 2012, p. 1). Vuelve con mayor fuerza en Occidente el mito de la "nación", la "comunidad europea" y "América" (y la supuesta necesidad de volver al asimilacionismo en contra del "multiculturalismo"); mito reforzado cada vez que se producen actos terroristas, por ejemplo. Las minorías étnicas, los migrantes, en particular los migrantes poscoloniales, los refugiados constituyen el principal público objetivo que atacan dichos "nacionalismos".

¿Cómo explicar esta ambivalencia consistente en que, por un lado, el mundo dispone de un número cada vez mayor de instrumentos jurídicos de promoción y protección de los derechos humanos de las minorías étnicas y culturales; y, por el otro, algunos Estados, principalmente los del primer mundo, adoptan políticas migratorias restrictivas poco hospitalarias y tienden a volver al asimilacionismo, dando la espalda al multiculturalismo por razones poco justificadas (entre ellas, el miedo al terrorismo)? En esta ambivalencia, los migrantes poscoloniales son doblemente víctimas: por ser migrantes (algunos son indocumentados o están a la espera del estatus de refugiados) y por ser excolonizados (provenientes de antiguas colonias).

\section{Mito de la nación y sus fetichismos en un mundo líquido y en un nuevo internacionalismo}

Paradójicamente, hoy (más que nunca) las sociedades territorializadas, en particular en el primer mundo, son afectadas por las culturas des-territorializadas de los inmigrantes; afectaciones que van más allá de la cuestión "folklórica" de "vestimenta, cocina y música" (Kymlicka, 2012, p. 4) para cuestionar la idea, la narración o el mito del Estadonación y sus fetichismos (lengua nacional, territorio nacional, identidad nacional, etc.). Vamos a ilustrarlo con un episodio real: 
Una manifestación de inmigrantes 'ilegales' hispanos (como los llaman en los Estados Unidos), bajo la consigna de "Nosotros también somos (Norte) América”, cantaron fervorosamente el himno estadounidense... en castellano... Como no era para menos, el acto fue recibido con apenas contenida furia por el presidente Bush, quien célebremente declaró en público: "El himno sólo se puede cantar en inglés” (Grüner, 2009, p. 27).

Con base en este episodio que motivó el intercambio entre dos grandes pensadoras contemporáneas Judith Butler y Gayatri Chakravorty Spivak en el libro Quién le canta al Estado-nación (2009), Eduardo Grüner hizo estas preguntas:

¿Qué es un estado-nación (y su reverso: ¿qué es un estado sin nación o una nación sin estado, como la Palestina?)? ¿Qué es una lengua nacional? ¿Qué es una “frontera”? ¿Qué es una identidad (nacional, étnica, cultural, política, sexual)? ¿Qué es un ciudadano (y su reverso: qué es ser un sin-estado)? (2009, pp. 32-33).

Los inmigrantes cantantes del himno nacional estadounidense trastocaron los fundamentos sólidos del Estado-nación, mostrando que se puede ser estadounidense siendo latino. Que la identidad estadunidense no es única, sino que existen varios modos de ser estadounidense: hablando castellano, siendo latinos. Que la ciudadanía estadunidense no se limita sólo a tener un pasaporte otorgado por el Estado y a otros ritos institucionalizados. Este episodio lleva indudablemente a lubricar el concepto sólido de la nación y sus fetichismos en un contexto posnacional, poscolonial y multicultural. Estas preguntas, planteadas por este episodio aparentemente anodino, cobran toda su agudeza

En una era como la nuestra, toda ella "sobredeterminada" por las travesías, casi siempre trágicas, de cuerpos desplazados, “des-territorializados" y obligados a "re-territorializarse" pero ya como membra disjecta, como retazos, restos, desechos: desde los millones conducidos en trenes a los campos de concentración nazis a los contingentes de emigrantes forzados por las "guerras posmodernas" y 
las "limpiezas étnicas", pasando por "ilegales" y los "sans-papiers" que pueblan las metrópolis ex-colonialistas si no es que han terminado antes en el fondo del mar, el mundo parece haber devenido un maelstrom de "flujos rizomáticos", de multitudes a la deriva, pero compuestos de ruinas antes que -con las excepciones que cada uno podrá citar- de sanos re-dimensionamientos del espacio territorial, simbólico-cultural o subjetivo (Grüner, 2009, pp. 34-35).

Las migraciones reconfiguran definitivamente nuestro mundo actual. Por ejemplo, las grandes olas de migrantes y refugiados, provenientes del Oriente Medio, del África, de América Latina, etc., (gran parte de ellos son originarios de países ex colonizados), nos muestran el fracaso del actual sistema global: tanto en la producción desenfrenada e incontrolable de los factores de producción del desarraigo (principalmente los factores humanos tales como conflictos asesinos, guerras, acopio masivo de tierras, contaminación de la tierra y el agua, el resurgimiento de la minería para obtener los metales) como en su incapacidad para responder a él. Los distintos rostros del desarraigo deambulan y erran en el mundo y, en especial, en las fronteras (el Mediterráneo, las fronteras entre los Estados Unidos de América y México, el mar Caribe, el mar de Andamán, etc.) y en las grandes ciudades de los países de primer mundo (Madrid, Barcelona, Miami, Los Ángeles, Nueva York, París, etc.), en busca de protección internacional y acogida.

Otra prueba de lo anterior es que se dice que estamos viviendo la segunda mayor crisis de refugiados en el mundo, después de la Segunda Guerra Mundial; como consecuencia de ello, existe una grave crisis humanitaria y también de protección de los derechos de los refugiados (algunos de ellos, recluidos en campamentos de refugiados en Grecia; y otros, listos para ser repatriados a Turquía y de allí a sus países de origen), debido a la negativa de la Unión Europea que, en vez de acoger a tales refugiados de acuerdo con lo estipulado por el derecho internacional de los derechos humanos [Convención de las Naciones Unidas sobre el Estatuto de Refugiados (Ginebra, 1951)], prefiere pactar un acuerdo político muy cuestionado con la Turquía. 
En este contexto, ¿qué significa la identidad? Roger Bartra cuestiona el concepto estático-monolítico-esencialista-jerárquico de la identidad, en particular la identidad promovida por el proyecto de la modernidad eurocéntrica (que no da cabida a otras identidades y que se cree superior a ellas). A través de una relectura del poema La tierra baldia (The Waste Land) publicado por T. S. Eliot en 1922, Roger Bartra desmitifica la aparente solidez de las construcciones estatales modernas del Occidente supuestamente arraigadas en sociedades homogéneas (naciones) y cimentadas en valores comunes y grandes relatos; por lo que, tal como lo dijo Ricard Zapata (2010, p. 28) "los Estados ven las migraciones con mucha cautela, puesto que la interpretan en términos de sus efectos sobre la estructura social e identitaria de sus sociedades".

Efectivamente, en el actual contexto de la globalización, Roger Bartra señala que los Estados nacionales modernos de Occidente son cada vez más lubricados y licuados por "flujos sociales que alientan formas inestables de empleo, responsabilidades económicas que huyen de los territorios delimitados, movilidades globales que viven en la incertidumbre, oleajes y vaivenes políticos que no respetan las soberanías estatales antiguas, derramas de población que provienen de remolinos caóticos en la periferia del mundo" (2007, pp. 39-40). Las sociedades modernas occidentales son humedecidas por las culturas líquidas (desterritorializadas) constituidas por "la presencia masiva de los sectores de inmigrados y de ciudadanos descendientes de extranjeros que conforman los espacios líquidos", y cuya liquidez "denota tanto su carencia de tierra como su origen fluido y su condición inestable" (Bartra, 2007, p. 46).

Desde la tierra baldía dejada por la pétrea modernidad 6 , "la masa de ciudadanos 'normales', que no posee un origen 'extraño' y que aparentemente no sufre problemas de identidad, comienza a aparecerse a la condición de los 'otros'”, señala Roger Bartra (2007, p. 51). Las identidades se vuelven cada vez menos sólidas, en virtud

6 Son metáforas utilizadas por el poeta T. S. Eliot en su poema The Waste Land y que retoma Roger Bartra. 
de los contactos con extranjeros y culturas foráneas. Los otros, los extraños, los extranjeros se expresan cada vez con mayor fuerza y ejercen también poder de atracción en los territorios de las sociedades occidentales.

Como resultado de ello, existe un carnaval de identidades cambiantes (incluyendo a un plexo de identidades extranjeras, foráneas, extrañas, "otras") a disposición de dichos ciudadanos, sin que necesiten anclarse en una identidad específica (la "original”, por ejemplo). Quienes se vanagloriaban antes de su identidad "clara y distinta" y de su fuerte arraigo al territorio van transitando cada vez más hacia el estilo de vida "migrante", es decir: un estilo des-territorializado (sin anclajes fijos), fluido, mestizo (articulando distintas identidades, culturas y estilos), etc. De esta manera, la presencia de los migrantes y las subjetividades desterritorializadas va reconfigurando de cierta manera a las sociedades y los ciudadanos del Occidente, a pesar de que sus Estados mantienen sus esfuerzos por "proteger" la identidad de sus sociedades y sus ciudadanos, cerrando sus fronteras, endureciendo sus políticas migratorias y de asilo e imponiendo pautas culturales a los extranjeros (el aprendizaje de las lenguas nacionales occidentales, por ejemplo).

En este contexto, se pregunta también Homi Bhabha (2002): ¿Qué es la cultura? Según él, esta pregunta se debe relacionar con la presencia masiva de los migrantes (cuerpos desplazados y des-territorializados) que han logrado arribar a algunas sociedades de llega$\mathrm{da}$, a pesar de todas las restricciones impuestas por sus respectivos Estados; presencia que nos lleva a preguntarnos también por el lugar o los lugares de la cultura. Son culturas des-territorializadas que llegan a sociedades ya establecidas (territorializadas) y luchan por tener un lugar allí en su calidad de "desterritorializadas" y defender sus derechos como "minorías culturales” en estas sociedades. Hoy ¿dónde está la cultura? ¿Se puede hablar de la cultura o, más bien, de las culturas en plural, incluyendo a las culturas desterritorializadas?

Según Homi Bhaba, la cultura (cualquiera) está ubicada hoy no en un aquí y ahora concreto (un territorio ubicado en el tiempo y el espacio), sino en el "campo del más allá”; es decir, en un momento de tránsito "donde el espacio y el tiempo se cruzan para producir figuras complejas de diferencia e identidad, pasado y presente, adentro y 
afuera, inclusión y exclusión” (2002, p. 17). La cultura no es estática: no está ni arriba ni abajo. Se encuentra en el entre-medio (in-between) de los límites, a la vez epistemológicos de las ideas etnocéntricas de corte esencialista o de las grandes narrativas del racionalismo posiluminista y los límites enunciativos de otras historias y otras voces disonantes (articuladas por "mujeres, colonizados, minorías, portadores de sexualidades vigiladas").

En este entre-medio Homi Bhabha ubica también lo que él llama la "demografía del nuevo internacionalismo". El antiguo internacionalismo estaba formado por las naciones o los Estados que buscaban cooperar para el beneficio propio (de hecho, lo siguen haciendo); el ejemplo más elocuente es la Organización de las Naciones Unidas (ONU). Sobre este concepto de internacionalismo se ha fundamentado el derecho internacional con base en la siguiente tríada, establecida por Vattel en su libro Le droit des gens, a saber: Estado-Relaciones entre Estados-Guerra (Oslé, 2013, p. 2013). En este sentido, el derecho internacional se ha constituido en un sistema interestatal, basado en la soberanía de los Estados que se relacionan entre ellos y a veces rompen estas relaciones mediante la guerra (cuando definitivamente no hay otra manera de solucionar los litigios).

Sin embargo, el "nuevo internacionalismo" que estamos viviendo hoy da un lugar central no a los Estados y su soberanía (mucho menos a la guerra, que es uno de los principales factores de desarraigo), sino a la demografía formada por "la historia de la migración poscolonial, las narrativas de la diáspora cultural y política, los grandes desplazamientos sociales de campesinos y aborígenes, las poéticas del exilio, la sombra de los refugiados políticos y económicos" (Bhabha, 2002, p. 21). El "nuevo internacionalismo" está constituido por subjetividades en tránsito, des-territorializadas, y cuyas identidades no están ancladas sino que fluyen, migran constantemente y se hibridizan.

Por lo mismo, la diáspora cobra una importancia fundamental, a tal punto que a veces es más representativa política y económicamente de sus países en el extranjero que la misma representación consular (o la embajada) de sus respectivos Estados. Las diásporas son comunidades que, "a pesar de su dispersión a partir de un territorio", 
se organizan en varios países, manteniendo ciertos lazos, un "sentimiento de pertenencia" a una "identidad colectiva" o ciertas "recomposiciones identitarias", en torno a "la memoria del exilio y de una herencia cultural o religiosa” (De Wenden, 2012, p. 19). Estas nuevas formas de comunidades desterritorializadas ocupan su lugar no sólo en las sociedades de acogida en las que se encuentran, sino que también tienen gran poder de representatividad de sus respectivos países en el escenario internacional.

\section{¿Cómo superar el mito de la nación, el desarraigo y el sistema global poscolonial por medio de un nuevo multiculturalismo?}

El mito de la nación y sus fetichismos sólo puede ser superado por la vigorosa acción de esta creciente penetración de los flujos migratorios globales y las subjetividades poscoloniales en los intersticios de las sociedades territorializadas y en el escenario internacional. El reto es grande ya que, a pesar de que hayan aceptado perder su control sobre la economía, la política y la cultura (cada vez más transnacionalizadas) en el actual sistema global, los Estados -principalmente los del primer mundo- renacionalizan cada vez más sus políticas migratorias (Sassen 1996) reafirmando su soberanía sobre los flujos de extranjeros, incluso a costa de vulnerar el derecho internacional de los derechos humanos.

Sin embargo, los flujos migrantes, las subjetividades poscoloniales, las diásporas y, en general, la "demografía del nuevo internacionalismo" irrumpe decididamente en dichos Estados para cuestionar el mito de la nación y sus fetichismos (la ciudadanía, la identidad, la soberanía) y para reclamar, defender y ejercer sus derechos humanos. Se vuelve muy pertinente esta pregunta que hace Will Kymlicka: dado que "las personas tienen un profundo vínculo con su propia cultura, ¿no deberíamos permitir que los inmigrantes recreasen sus propias 
culturas societales"? (1996, p. 135) De hecho, el pensador canadiense reconoce que "muchas de las naciones existentes fueron inicialmente formadas por colonos desarraigados que se asentaron en una nueva tierra. Este es el caso de las naciones inglesa y francesa en Canadá y en los Estados Unidos" (Kymlicka, 1996, p. 135).

La "demografía del nuevo internacionalismo", principalmente los jóvenes migrantes y los migrantes de la segunda generación, vienen haciendo la apuesta por integrar de manera transnacional sus distintas identidades, articulando sus culturas de origen y llegada en las dos direcciones sugeridas por Will Kymlicka, a saber: "que la sociedad mayoritaria se adapte a los inmigrantes, de la misma manera que los inmigrantes deban adaptarse a ella” (1996, p. 137). Lo que, por un lado, obliga a que los Estados de llegada combatan en sus respectivas sociedades los prejuicios y la discriminación contra los inmigrantes y las minorías y no los pongan en desventaja con respecto a la cultura societal mayoritaria; y, por el otro, a que los inmigrantes hagan mayores esfuerzos por integrarse en las sociedades de acogida, pero sin renunciar a sus propias culturas. Tal como lo venimos planteando en este capítulo, ha habido serios retrocesos en el combate de varios Estados contra la discriminación y a favor de la aceptación de los inmigrantes.

El caso específico de los tres rostros de desarraigados (los atrapados entre su lugar de origen y su lugar de llegada; los sin-Estados; los excluidos de los territorios de acogida) subrayan los límites de todas las propuestas multiculturalistas (incluida la de Will Kymlicka), en el sentido que no llegan a la raíz del problema que es justamente la cuestión de la justicia. Si bien, por ejemplo, Will Kymlicka incluso reconoce que "la justicia internacional obliga a que los países ricos redistribuyan recursos a los países pobres” para evitar que personas procedentes de países pobres se vean obligadas a emigrar hacia países ricos (aunque no estuviesen perseguidas en sus propios países); sin embargo, se queda corto a la hora de responder a la pregunta: “Cuáles serían los derechos de los inmigrantes en un mundo justo?” (Kymlicka 1996, p. 141).

La justicia va más allá de la simple acomodación de la diversidad cultural en la sociedad de llegada, por medio del reconocimiento 
e implementación de los derechos humanos y culturales de los inmigrantes a través de políticas multiculturales. La justicia también va más allá de la capacidad de cualquier Estado para "gobernar y manejar los problemas de diversidad y multiplicidad" con miras a construir la vida común. Justamente el desarraigo viene a decirnos que hay un gran plexo de personas, familias y comunidades que no encuentran un lugar en el mundo porque se les ha destruido su hogar y su mundo y también se les ha negado un nuevo lugar humano (de acogida de sus identidades y de derecho).

En consecuencia, el mundo está lleno de errantes y nómadas que no encuentran un lugar (geográfico y cultural) para habitar, sin hablar de los metecos ${ }^{7}$ (del griego, meta=cambio y oikos=casa); es decir, personas que cambiaron de país, pero el nuevo país nunca las ha aceptado ni a ellas ni a sus descendientes como sus huéspedes legítimos. Es el caso, por ejemplo, de los dominicanos de origen haitiano quienes están siendo desnacionalizados y condenados a la apatridia (simplemente por ser descendientes de migrantes haitianos) por culpa de la Resolución 168/13 del Tribunal Constitucional dominicano, a pesar de la reprobación y sanción de los principales organismos de la comunidad internacional (las agencias de las Naciones Unidades (ONU), la Corte y la Comisión de Derechos Humanos de la Organización de los Estados Americanos -OEA-) contra el Estado dominicano.

La justicia implica re-ajustar este mundo, en el que algunos países (principalmente excolonizadores) han cometido serias injusticias en contra de varios pueblos, cuyos ciudadanos se han visto obligados a buscar protección y mejores condiciones de vida en dichos países excolonizadores. La justicia nos conecta con la necesidad de luchar contra el actual sistema global poscolonial que encarna una nueva configuración de poder, pero que sigue manteniendo la hegemonía de unos países (primer mundo) sobre otros ya no bajo la legitimación colonial sino bajo nuevos discursos, mecanismos y procesos (por ejemplo, la democracia, el desarrollo y la lucha contra el terrorismo, etc.).

7 Concepto retomado de Reale y Antiseri (1988). 
La justicia obliga definitivamente a crear un nuevo multiculturalismo capaz de enfrentar radicalmente el actual sistema global a la vez neo-colonial y productor de desarraigo. Un nuevo multiculturalismo que promueva el establecimiento de relaciones simétricas entre todos los países, pueblos y naciones de la Tierra (incluso los que no tienen Estado) a través de estas tres acciones, entre otras:

a. Democratizar los espacios internacionales de deliberación y decisión de todos los pueblos de la tierra, por ejemplo, la Organización de las Naciones Unidas (ONU), en particular su Consejo de Seguridad, como nuevo punto de partida de una humanidad que rompa con el racismo (fundamentado en la supuesta jerarquía de unos pueblos sobre otros y la creencia de que los pueblos superiores deben gobernar a los otros).

b. Atacar de raíz los factores histórico-estructurales (por ejemplo, la neo-colonización actual de grupos, pueblos e incluso continentes -África, América Latina...- por la vía del capitalismo neoliberal global que los sigue despojando, desterritorializando, desarraigando y subalternizando a través de las desigualdades económicas, la estigmatización social, la invisibilidad cultural, la baja o inexistente representación política) que han contribuido a crear y mantener la jerarquía política, económica, epistémica e incluso jurídica de unos países, pueblos e "identidades" sobre otros.

c. Reparar integralmente (económica, política, simbólica y culturalmente) a tantos grupos étnicos y raciales, pueblos, naciones e incluso continentes que han sufrido durante siglos y siguen padeciendo hoy de innumerables injusticias y crímenes de lesa humanidad (como la esclavitud, por ejemplo) que derivan de la colonización y exigen reparación y restitución hoy en día, tal como lo reconoció la Conferencia de Durbán (Sudáfrica, 2001).

¿Habría otra manera de "salvar" hoy el multiculturalismo para que no siga siendo un simple paliativo aplicado por el mismo sistema global neo-liberal para mantener la hegemonía y jerarquía de las 
mismas sociedades y culturas (primer mundo) al interior de sus territorios y sobre el resto de la humanidad? ¿No romper con los mecanismos, estructuras y procesos políticos, económicos, educativos y socio-culturales actuales que hacen funcional el multiculturalismo al sistema global poscolonial (asimétrico y hegemónico) no equivaldría a destruir a la larga la heterogeneidad de los grupos subalternizados (minorías y grupos étnicos, nacionales, migrantes poscoloniales, diásporas) y cualquier posibilidad de crear relaciones simétricas entre estos últimos y los países o culturas hegemónicos?

\section{A modo de conclusiones}

Este recorrido por las categorías del "desarraigo", el "fenómeno de lo poscolonial" y la "cuestión multicultural" nos permitió ver que las tres categorías mencionadas están íntimamente vinculadas.

El desarraigo actual se da en un contexto poscolonial (reconfigurado por un nuevo sistema global hegemónico) y hace resurgir con ahínco la cuestión multicultural: ¿Cómo acoger, incluir e integrar a estos otros diferentes, extranjeros y excolonizados, particularmente en las sociedades excolonialistas?

Por otra parte, el fenómeno de lo poscolonial no se entiende sin tener claro que hay un nuevo sistema global que mantiene continuidades y rupturas con la colonización; en esta configuración persisten la jerarquía y hegemonía de los países excolonialistas sobre las sociedades descolonizadas, y se produce un nuevo desarraigo de ciudadanos poscoloniales a quienes se les niega un lugar en dichos países reacios a la multiculturalidad.

Finalmente, la cuestión multicultural es heredera de la cuestión colonial, ya que los migrantes poscoloniales en los actuales flujos se siguen enfrentando a la discriminación, al racismo y a otras barreras que dificultan su acogida e integración en las sociedades de llegada, debido a la vigencia del peso colonial-racista. Dichos migrantes son también desarraigados, pero en el sentido preciso que sus culturas o 
"identidades" desterritorializadas no tienen un lugar de acogida en los países excolonialistas.

La principal tarea consiste pues en "salvar" la heterogeneidad de los grupos subalternizados (minorías étnicas, nacionales, migrantes, poscoloniales) para que los países y grupos hegemónicos no sólo los "toleren" o los "incluyan" desde una visión "exótica" y "subalternizada" de las alteridades [(Zizek, 1998 y Bhabha, 1998, citados por Catherine Walsh (2009)] que, por ejemplo, exalta su "sabiduría etérea" y sus "costumbres encantadoras", pero las ve desde arriba y de modo despectivo. El nuevo multiculturalismo debe llevar a que dichos países reconozcan en serio que estas alteridades también son portadoras de culturas, conocimientos, experiencias, sabidurías e insumos valiosos para la construcción de una sociedad, una región y una humanidad más abiertas y justas.

Del mismo modo, es importante que, además de salvar la heterogeneidad de dichos grupos, el nuevo multiculturalismo deje de ser funcional al actual sistema global poscolonial, productor del desarraigo de ciudadanos originarios de excolonias y reproductor de la jerarquía de los mismos países excolonialistas en el escenario internacional.

Los flujos de migrantes y refugiados, las subjetividades poscoloniales desterritorializadas y las diásporas en general deben ser los actores centrales de este nuevo multiculturalismo ya que sólo ellos pueden ayudar a superar el mito de la nación y sus fetichismos, fluidificando las nociones de identidad y ciudadanía (por la articulación transnacional, dialógica y enriquecedora entre sus culturas de origen y destino) con miras a construir sociedades realmente multiculturales, relaciones simétricas entre el Norte y el Sur y una globalización humana, diversa, justa en el mundo. Una globalización digna de nuestra humanidad a la vez diversa y heterogénea.

Una globalización justa; es decir, que se ajuste a nuestra humanidad y a sus múltiples articulaciones y expresiones históricas, civilizatorias, culturales, sociales, políticas. 


\section{Bibliografía}

Álvarez Achandi, I. (2012). Introducción. En Álvarez Achandi, I. (Ed.). Mirando al Norte: Algunas tendencias de la migración latinoamericana (pp. 7-10). San José, Costa Rica: Facultad Latinoamericana de Ciencias Sociales (FLACSO).

Amnistía Internacional. (2013). Informe 2013. El estado de los derechos humanos en el mundo. Londres, Inglaterra: Oficina de Amnistía Internacional. Recuperado de http://files.amnesty.org/air13/ AmnestyInternational_AnnualReport2013_complete_es.pdf

Bartra, R. (2008). Territorios del otro y la otredad. Distrito Federal, México: Fondo de Cultura Económica.

Bauman, Z. (2013). La cultura en el mundo de la modernidad líquida. Distrito Federal, México: Fondo de Cultura Económica.

Bhabha, H. (2002). El lugar de la cultura. Buenos Aires, Argentina: Manantial.

Bobbio, N. (1991). El tiempo de los derechos. Madrid, España: Sistema.

Butler, J. \& Spivak, G. (2009). ¿Quién le canta al estado-nación? Lenguaje, política, pertenencia. Buenos Aires, Argentina: Paidós.

Castro-Gómez, S. \& Restrepo, E. (2008). Introducción. Colombianidad, población y diferencia. En Castro-Gómez, S. \& Restrepo, E. (Eds.). Genealogías de la colombianidad. Formaciones discursivas y tecnologías de gobierno en los siglos XIX y XX (pp. 10-41). Bogotá, Colombia: Editorial Pontificia Universidad Javeriana.

Comisión Económica para América Latina y el Caribe (CEPAL). "Cerca de 28,5 millones de latinoamericanos y caribeños viven fuera de sus países de origen”. 11 de noviembre de 2014. Recuperado de: http://www.cepal. org/es/comunicados/cerca-de-285-millones-de-latinoamericanos-y-caribenos-viven-fuera-de-sus-paises-de

De Wenden, C. W. (2012). Atlas des migrations. Un équilibre mundial à inventer. París, Francia: Autrement.

Eliot, T.S. (2001). La Tierra baldía. Barcelona, España: Círculo de lectores (trad. Juan Malpartida).

Glissant, E. (1997). Le discours antillais. París, Francia: Gallimard. 
Gogol, E. (2004). El concepto del otro en la liberación latinoamericana. La fusión del pensamiento filosófico emancipador y las revueltas sociales. Bogotá, Colombia: Desde Abajo.

Grüner, E. (2009). Prólogo. Sobre el estado-bifurcación y otras perplejidades. En Butler, J. \& Spivak, G. ¿Quién le canta al estado-nación? Lenguaje, política, pertenencia (pp. 13-42). Buenos Aires, Argentina: Paidós.

Forero Reyes, Y. M. (2008). Epifanias de la identidad. La comprensión multicultural de Charles Taylor. Bogotá, Colombia: Editorial Pontificia Universidad Javeriana.

Hall, S. (2000). Conclusion: the multi-cultural. En Esse, B. (Ed.) Un/settled Multiculturalisms: Diasporas, Entanglements, 'Transruptions' (pp. 209241). London, England: Zeb Books.

Kymlicka, W. (2012). Multiculturalism: Success, Failure, and The Future. Washington, D.C., USA: Migration Policy Institute (MPI).

Kymlicka, W. (1996). Ciudadanía multicultural. Una teoría liberal de los derechos de las minorías. Barcelona, España: Paidós.

Kymlicka, W. (2007). Las odiseas multiculturales. Las nuevas politicas internacionales de la diversidad. Barcelona, España: Paidós.

Louidor, W. E. (2016). Articulaciones del desarraigo en América Latina. El drama de los sin hogar y sin mundo. Bogotá, Colombia: Editorial Pontificia Universidad Javeriana.

Reale, G. \& Antiseri, D. (1988). Historia del pensamiento filosófico y científco. Tomo primero: Antigüedad y Edad Media. Barcelona, España: Herder.

Sassen, S. (1996). Losing control? Sovereignty in Age of Globalization. New York: Colombia University Press.

Saskia, S. (2015). "Massive loss of habitat" triggers new array of migrations. Interview with Saskia Sassen". Truman Factor, 21 de noviembre de 2015. Recuperado de http://trumanfactor.com/2015/saskia-sassen-interview-2-15136.html

United Nations, Department of Economic and Social Affairs, Population Division. (2016). International Migration Report 2015: Highlights (ST/ESA/SER.A/375). New York, USA: United Nations Printing Office. Recuperado de http://www.un.org/en/development/desa/population/ migration/publications/migrationreport/docs/MigrationReport2015_ Highlights.pdf 
Walsh, C. (2009). Interculturalidad, Estado, sociedad. Luchas (de)coloniales de nuestra época. Quito, Ecuador: Andina Simón Bolívar/Abya-Yala

Zapata, R. (2010). Migración y crisis económica en una perspectiva global. En Vélez, D. \& Gómez, A. (Eds.). Migraciones internacionales. Crisis mundial, nuevas realidades, nuevas perspectivas. Bogotá, Colombia: Universidad Nacional de Bogotá, Digiprint Editores E.U. 
